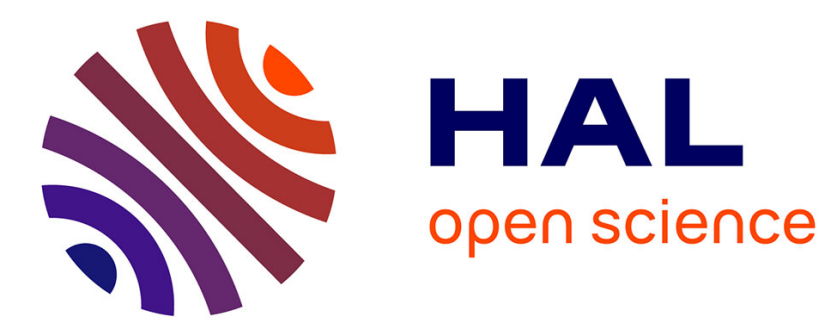

\title{
Raman Scattering Experiments on Unfilled Skutterudite CoSb3 under High Pressure and High Temperature
}

\author{
Romain Viennois, T. Kume, M. Komura, L. Girard, A. Haidoux, Jérome \\ Rouquette, M. M Koza
}

\section{- To cite this version:}

Romain Viennois, T. Kume, M. Komura, L. Girard, A. Haidoux, et al.. Raman Scattering Experiments on Unfilled Skutterudite CoSb3 under High Pressure and High Temperature. Journal of Physical Chemistry C, 2020, 124 (42), pp.23004-23012. 10.1021/acs.jpcc.0c06703 . hal-02997372

\section{HAL Id: hal-02997372 \\ https://hal.science/hal-02997372}

Submitted on 10 Nov 2020

HAL is a multi-disciplinary open access archive for the deposit and dissemination of scientific research documents, whether they are published or not. The documents may come from teaching and research institutions in France or abroad, or from public or private research centers.
L'archive ouverte pluridisciplinaire HAL, est destinée au dépôt et à la diffusion de documents scientifiques de niveau recherche, publiés ou non, émanant des établissements d'enseignement et de recherche français ou étrangers, des laboratoires publics ou privés. 


\title{
Raman Scattering Experiments on Unfilled Skutterudite CoSb3 under High Pressure and High Temperature
}

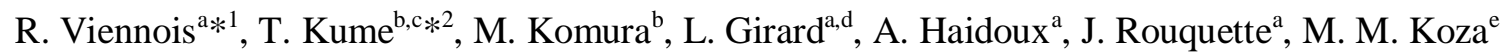 \\ ${ }^{a}$ ICGM, Université Montpellier, CNRS, ENSCM, Montpellier, France \\ ${ }^{\mathrm{b}}$ Dept. of Electrical, Electronic \& Computer Engineering, Faculty of Engineering, Gifu University, 1- \\ 1 Yanagido, Gifu, 501-1193 Japan \\ ${ }^{\mathrm{c}}$ International Joint Department of Integrated Mechanical Engineering of IITG and GU, the Graduate \\ School of Engineering, Gifu University, 1-1 Yanagido, Gifu, 501-1193 Japan \\ ${ }^{\mathrm{d}}$ ICSM, Université Montpellier, CNRS, ENSCM, Montpellier, France \\ ${ }^{\mathrm{e}}$ Institut Laue Langevin, 71 Avenue des Martyrs, CS 20156, F-38042 Grenoble, France.
}

\begin{abstract}
In the present work, we study the anharmonicity of the unfilled $\mathrm{CoSb}_{3}$ skutterudite from the pressure and temperature dependence of the Raman-active modes. A full assignment of the Raman-active modes of $\mathrm{CoSb}_{3}$ was performed for the first time. Significant changes in the Raman spectrum are observed above $27 \mathrm{GPa}$ and attributed to the insertion of antimony atoms within the cages under high external pressure. We report the lattice dynamics of $\mathrm{SbCo}_{4} \mathrm{Sb}_{12}$ by DFT calculations and find very low energy optical modes due to the antimony guest atoms with the cage framework. We report the isothermal Grüneisen parameters of the Raman-active modes, which are larger and approach 2 for the highest energy modes. From analysis of the temperature and pressure dependence of the Raman-active modes, we found that the implicit volume contribution is the dominant contribution for the highest energy Raman-active modes whereas both the implicit volume contribution and the explicit anharmonic contribution have same magnitude for the other Raman-active modes.
\end{abstract}

Keywords: thermoelectric, skutterudite, lattice dynamics

\footnotetext{
*1 Corresponding author: romain.viennois@umontpellier.fr

*2 Corresponding author: kume@gifu-u.ac.jp
} 


\section{Introduction}

Skutterudite is a mineral discovered in Skutterud, Norway with the chemical formula $\mathrm{Co}_{0.504} \mathrm{Fe}_{0.21} \mathrm{Ni}_{0.122} \mathrm{Cu}_{0.184} \mathrm{As}_{3.04} \mathrm{~S}_{0.05}$ and reported to have cubic symmetry by Oftedal. ${ }^{1}$ Later on, it was shown that several compounds with the $\mathrm{MX}_{3}$ chemical formula $(\mathrm{M}=\mathrm{Co}, \mathrm{Rh}$ or $\mathrm{Ir}$ and $\mathrm{X}=$ pnictogen) have the same cubic symmetry with space group $\mathrm{Im}-3 .{ }^{2-6}$ The skutterudite structure $\mathrm{MX}_{3}$ can be derived from the perovskite structure of $\mathrm{ReO}_{3}$ by slightly tilting the octahedra formed by the oxygens. The stoichiometry of the skutterudite structure may be alternatively represented by its unit cell as $\square_{2} \mathrm{M}_{8} \mathrm{X}_{24}$ with the two voids corresponding to a (2a) Wyckoff site. It is then referred to as an unfilled skutterudite ${ }^{2-7}$ whereas with filled voids as in $\mathrm{R}_{2} \mathrm{M}_{8} \mathrm{X}_{24}$ or $\mathrm{RM}_{4} \mathrm{X}_{12}(\mathrm{R}=$ rare-earth, alkaline-earth, alkaline metals, $\mathrm{U}, \mathrm{Th} ; \mathrm{M}=\mathrm{Fe}, \mathrm{Ru}, \mathrm{Os}$ and $\mathrm{X}=$ pnictogen) it is called filled skutterudite..$^{7-9}$ The physical properties of unfilled skutterudites were first studied in the 1950s and studies were very few until the 1980s. ${ }^{10-12}$ They suggested that some of those compounds are narrow-gap semiconductors with some potential for thermoelectric applications. ${ }^{10-12}$ During the 1980s, infrared studies confirmed the semiconducting character of many skutterudites, outlined their vibrational properties ${ }^{13-15}$ and a more accurate study of the crystal structure of $\mathrm{CoSb}_{3}$ was performed. ${ }^{16}$ In the middle of 1990 s, the potential of the unfilled skutterudites for thermoelectricity was rediscovered. ${ }^{17-21}$ Filled skutterudites were studied for the first time and found to be promising for thermoelectric applications. ${ }^{22-24}$ The performance of thermoelectric materials is characterized by the dimensionless figure of merit $\mathrm{ZT}=\sigma \alpha^{2} \mathrm{~T} / \kappa$, where $\sigma$ is the electrical conductivity, $\alpha$ is the Seebeck coefficient, $\mathrm{T}$ is the temperature and $\kappa$ is the thermal conductivity which has a lattice contribution $\kappa_{1}$ and an electron contribution $\kappa_{\mathrm{e}}{ }^{7,25}$ The most widely used commercial thermoelectric materials are alloys based on $\mathrm{Bi}_{2} \mathrm{Te}_{3}$ and on PbTe with $\mathrm{ZT}$ of about $1 .{ }^{25}$ The best $\mathrm{ZT}$ for the p-type skutterudites was found to be around 1.4 at $600^{\circ} \mathrm{C}$ for the filled skutterudite $\mathrm{CeFe}_{3.5} \mathrm{Co}_{0.5} \mathrm{Sb}_{12}$ ${ }^{24}$ whereas the best ZT for the n-type skutterudites was found around $1.7-1.9$ at $550^{\circ} \mathrm{C}$ for the partially multi-filled skutterudite (R,R',R'")Co $\mathrm{C}_{4} \mathrm{Sb}_{12} .{ }^{26,27}$ Recently, the thermoelectric properties of n-type unfilled skutterudite $\mathrm{CoSb}_{3}$ have been improved with tellurium doping $\left(\mathrm{ZT}=1.1\right.$ at $\left.550^{\circ} \mathrm{C}\right){ }^{28}$ and with tellurium and silicon codoping together with significant porosity $\left(\mathrm{ZT}=1.6\right.$ at $\left.550^{\circ} \mathrm{C}\right) .{ }^{29}$ The most promising n-type skutterudite compound for thermoelectric applications is thus $\mathrm{CoSb}_{3}{ }^{7,26-29}$ and in 
addition it is made of more abundant and less toxic elements than other skutterudites. $\mathrm{CoSb}_{3}$ is a narrowgap semiconductor with an indirect bandgap and its valence band has linear dispersion. ${ }^{30-31}$ Recent studies indicate the possibility of a conventional to topological phase transition. ${ }^{32-33}$ There is no clear consensus about the experimental value of the indirect bandgap whereas the optical direct bandgap was recently found to be $0.23 \mathrm{eV} .{ }^{34}$ DFT calculations are well known to underestimate the bandgap of materials. ${ }^{35,36}$ In the case of CoSb3, only recently more accurate calculations using meta-Generalized Gradient Approximation (meta-GGA) exchange-correlation functional or GW method were reported. ${ }^{37}$ From these methods, the indirect bandgap is about $0.33 \mathrm{eV} .{ }^{37}$ The knowledge of the lattice dynamics of thermoelectric materials is a fundamental step to understand their thermal conductivity. In a previous work, we have shown that the vibrations of the guest atoms in the filled skutterudites form proper eigenmodes with the host-lattice. ${ }^{38}$ They are of appreciably low energy which is a fundamental feature for explaining their low thermal conductivity. ${ }^{39-42}$ Concerning $\mathrm{CoSb}_{3}$, its lattice dynamics was studied by Infrared spectroscopy, ${ }^{13-15}$ Raman spectroscopy, ${ }^{43-45}$ inelastic neutron scattering, ${ }^{46}$ inelastic and resonant X-ray scattering ${ }^{47,48}$ as well as by harmonic ${ }^{49-51}$ and anharmonic ${ }^{40,52,53}$ DFT and molecular dynamics calculations. ${ }^{51,54}$ However, so far neither the mode Grüneisen parameters nor experimental data of the anharmonicity of the lattice dynamics of $\mathrm{CoSb}_{3}$ have been reported, which are of fundamental importance for a good understanding of the phonon scattering mechanisms in the thermal conductivity. Raman experiments under pressure have been recently performed on another unfilled skutterudite $\mathrm{CoP}_{3}$ and its mode Grüneisen parameters were obtained. ${ }^{55}$ Also, the effect of pressure on the guest mode of $\mathrm{LaFe}_{4} \mathrm{Sb}_{12}$ was recently calculated by Martinotto et al. ${ }^{56}$ Moreover, a recent theoretical work has reported an improvement of the thermoelectric properties of $\mathrm{CoSb}_{3}$ under high pressure. ${ }^{57}$ Several studies have discussed the effect of pressure on the crystal structure of $\mathrm{CoSb}_{3}$ and reported the equation of states and the bulk modulus of $\mathrm{CoSb}_{3}$ and other skutterudites. ${ }^{58-65}$ They also reported an antimony insertion reaction under high external pressure in the antimonide and arsenide unfilled skutterudites above $20 \mathrm{GPa}$ at room temperature ${ }^{60-65}$ and at pressures lower than $10 \mathrm{GPa}$ under high pressure-high temperature (HP-HT) conditions. ${ }^{64,65}$ Until now, only thermoelectric and transport properties of these $\mathrm{Sb}_{\mathrm{x}} \mathrm{Co}_{4} \mathrm{Sb}_{12-\mathrm{x}}$ samples were studied. ${ }^{65}$ Other properties such as lattice dynamics under high pressure of $\mathrm{CoSb}_{3}$ are missing. 
The aim of the present work is to study $\mathrm{CoSb}_{3}$ by Raman spectroscopy under high pressure and high temperature. This will permit to determine the mode Grüneisen parameters, the different contributions of the anharmonicity as well as the effect of the antimony insertion reaction under high external pressure on the dynamics of the compound. In addition, we have computed the lattice dynamics of $\mathrm{SbCo}_{4} \mathrm{Sb}_{12}$ in order to approximate the dynamics of the antimony guests.

\section{Methods}

The polycrystalline $\mathrm{CoSb}_{3}$ sample used for the high-pressure experiments was obtained by using pieces of antimony and cobalt placed in stoichiometric amount in a carbon-coated quartz tube. This was heated at $1050^{\circ} \mathrm{C}$ for $48 \mathrm{~h}$, then cooled down to $900^{\circ} \mathrm{C}$ at $6^{\circ} \mathrm{C} / \mathrm{h}$, then to $800^{\circ} \mathrm{C}$ at $15^{\circ} \mathrm{C} / \mathrm{h}$ and finally to room temperature at $100^{\circ} \mathrm{C} / \mathrm{h}$. X-ray diffraction confirmed that the majority phase is $\operatorname{CoSb}_{3}(76 \%)$ and show the presence of significant amounts of antimony (24\%). See the Supplementary Information for the details. The single-crystals of $\mathrm{CoSb}_{3}$ were obtained using the iodine transport method in a gradient furnace. $\mathrm{SbI}_{3}$ was used as agent for the chemical transport. We have performed single-crystal X-ray diffraction on one piece cut from a crystal and confirmed that we have obtained single-crystals of $\mathrm{CoSb}_{3}$ of good quality. See the Supplementary Information for the details. The atomic positions are reported in Table 1 .

Raman scattering experiments under high pressure were performed using a Raman spectrometer equipped with Peltier cooled CCD and with a green laser $(\lambda=532 \mathrm{~nm})$. The spectral resolution is about 1-2 $\mathrm{cm}^{-1}$. High-pressure measurements were performed within a membrane diamond anvil cell (DAC) with low fluorescence diamonds. The samples were placed into a $100 \mu \mathrm{m}$ chamber drilled in an indented stainless-steel gasket. The pressure transmitting medium was dense argon that has no Raman signal. Solid Ar is extremely compressible and provides nearly quasi-hydrostatic conditions. ${ }^{66}$ The fluorescence of ruby was used as a pressure gauge. ${ }^{67}$ The pressure error is estimated to about $0.1 \mathrm{GPa}$. Care has been done to avoid the presence of antimony in our experiments. See below for a discussion. Raman scattering experiments above room $\mathrm{T}$ were performed with a Horiba Jobin-Yvon Labram Aramis spectrometer equipped with Peltier cooled CCD and a He-Ne laser $(\lambda=633 \mathrm{~nm})$. The spectral resolution of the experiment is about $1 \mathrm{~cm}^{-1}$. The high temperature experiments were performed in the oven of a 
Linkham TS15000 heating stage under the objective (X50) of an Olympus microscope. The temperature was measured with a Pt resistance at the bottom of the oven. The temperature error is estimated to about $10{ }^{\circ} \mathrm{C}$ at the highest temperature.

In all the Raman experiments, the spectra were obtained in a backscattering configuration using a microscope device that allows the incident light to be focused on the sample as a spot of several micrometers diameter.

The Density Functional Theory (DFT) calculations were based on Projector Augmented Wave (PAW) pseudopotentials and the Perdew-Burke-Ernzerhof (PBE) exchange-correlation functional using the Vienna $a b$ initio Simulation Package (VASP). ${ }^{68,69}$ For all calculations, an energy cut-off of $350 \mathrm{eV}$ was applied, the force convergence was $10^{-5} \mathrm{eV} / \mathrm{A}$ and the energy convergence was $10^{-10} \mathrm{eV}$. We applied a k-meshes of $11 \times 11 \times 11$ for both $\square \mathrm{Co}_{4} \mathrm{Sb}_{12}\left(\mathrm{CoSb}_{3}\right)$ and $\mathrm{SbCo}_{4} \mathrm{Sb}_{12}$. The relaxed lattice parameters found are $9.11043 \AA$ for $\square \mathrm{Co}_{4} \mathrm{Sb}_{12}$ and $9.1865 \AA$ for $\mathrm{SbCo}_{4} \mathrm{Sb}_{12}$, thus the intercalation of Sb guest atoms at the (2a) site increases the lattice parameter by about $0.8 \%$. The space group is Im-3 for both compounds, as in the experiments. ${ }^{5,16,21,68,70}$ The experimental values of the lattice parameter of $\square \mathrm{Co}_{4} \mathrm{Sb}_{12}$ at room temperature are between $9.016 \AA$ and $9.0385 \AA$ in the litterature, ${ }^{5,16,21,70}$ whereas one finds $9.0369(3) \AA$ for the case of our single-crystal and 9.03890(6) $\AA$ for our polycrystals. This can be compared to the lattice parameter of $9.129 \AA$ for $\mathrm{Sb}_{0.8} \mathrm{Co}_{4} \mathrm{Sb}_{11.2}$ obtained by HP-HT synthesis, ${ }^{68}$ which corresponds to an increase of $1 \%$ to $1.25 \%$. By comparison with our calculations, one can conclude that the Sb vacancies have only little effect on the volume. The positions of the atoms calculated for $\square \mathrm{Co}_{4} \mathrm{Sb}_{12}$ and $\mathrm{SbCo}_{4} \mathrm{Sb}_{12}$ are reported in Tables 1 and 2. The positions of the $\mathrm{Sb}$ atoms of the framework are slightly different from the experiments ${ }^{65}$ and change slightly between $\square \mathrm{Co}_{4} \mathrm{Sb}_{12}$ and $\mathrm{SbCo}_{4} \mathrm{Sb}_{12}$. We also note that in the experiments, the $\mathrm{Sb}_{\text {guest }}$ atoms are off-centered ${ }^{65}$ while they are on-centered in the calculations. This could be due to the presence of Sb vacancies in the experiments. We have calculated the curve of energy vs volume of $\square \mathrm{Co}_{4} \mathrm{Sb}_{12}$ at different constant volumes and fitted it with the Vinet equation. ${ }^{71} \mathrm{We}$ found a bulk modulus of $\mathrm{B}=83 \mathrm{GPa}$ and a pressure derivative of $\mathrm{dB} / \mathrm{dP}=6.3$. The bulk modulus is close to the experimental values found by Shirotani et al using the Birch-Murnaghan equation (B $=81 \mathrm{GPa}$ and $\mathrm{dB} / \mathrm{dP}=6.1)^{58}$ but much smaller than the value found by Kraemer et al using the Vinet equation $(\mathrm{B}=$ 
97.1 GPa and $\mathrm{dB} / \mathrm{dP}=4)^{59}$ or by Kraemer et al using the Birch-Murnaghan equation (B = $93 \mathrm{GPa}$ and $\mathrm{dB} / \mathrm{dP}=5) .{ }^{60}$

Lattice dynamics calculations were carried out with the direct method from the Hellmann-Feynman (HF) forces computed on the relaxed skutterudite structures. The HF forces were derived by displacing atoms from their equilibrium positions by $0.03 \AA$ along non-equivalent high-symmetry directions. The lattice dynamics properties were computed from the HF forces by the diagonalization of the dynamical matrix with the software package Phonon. ${ }^{72}$ For calculating the mode Grüneisen parameters $\gamma_{1}=-\operatorname{dln} \omega_{1} / \mathrm{d} V$, we calculated the mode frequencies $\omega_{1}$ for different volumes $V$.

In the present calculations, the spin-orbit coupling (SOC) has not been included. However, for heavy atoms like Bi or Tl, the SOC is not negligible. ${ }^{73}$ The SOC will affect less the Sb because it is much lighter than these atoms. Indeed, Haussermann et al was able to accurately describe Sb under pressure with the different transitions to the high pressure Sb phases without taking into account the SOC. ${ }^{74}$ This means that the effect of SOC for $\mathrm{Sb}$ is small. Among all DFT calculations performed for $\mathrm{CoSb}_{3}$, only Smith et al ${ }^{32}$ have examined the case of the SOC. They studied the effect of both tetragonal distortion and SOC. They found that the effect SOC is small, but when coupled to a tetragonal distortion, it opens the gap required to give a topological insulator. Note however that the calculations were performed using a GGA exchangecorrelation functional as in the later study of the same group, ${ }^{33}$ which underestimates the bandgap of $\mathrm{CoSb}_{3}$ as Khan et al ${ }^{37}$ have shown.

\section{Results}

In the unfilled skutterudite $\mathrm{CoSb}_{3}$, there are 16 atoms in the primitive unit cell and therefore 48 different vibrational modes with 3 acoustic and 45 optic modes. The presentation in an irreducible decomposition of the optic modes is the following:

$$
\Gamma=2 \mathrm{~A}_{\mathrm{g}} \oplus 2 \mathrm{E}_{\mathrm{g}} \oplus 4 \mathrm{~T}_{\mathrm{g}} \oplus 2 \mathrm{~A}_{\mathrm{u}} \oplus 2 \mathrm{E}_{\mathrm{u}} \oplus 7 \mathrm{~T}_{\mathrm{u}}
$$

The modes with $\mathrm{A}_{\mathrm{g}}, \mathrm{E}_{\mathrm{g}}$ and $\mathrm{T}_{\mathrm{g}}$ symmetries are Raman-active and thus there are 8 Raman-active modes. The 7 modes with $T_{u}$ symmetry are infrared-active modes. In the case of the filled skutterudites 
$\mathrm{RCo}_{4} \mathrm{Sb}_{12}$, the $\mathrm{R}$ guest atom located on the (2a) site and the corresponding additional mode has $\mathrm{T}_{\mathrm{u}}$ symmetry and there are therefore 8 infrared-active modes.

We report in Fig. 1 the Raman spectrum of the single-crystal sample. The energies of the Raman-active modes are listed in Table 3. The results are in good agreement with the most recent Raman scattering experiments. ${ }^{45}$ We notably confirm the doublet at $175 \mathrm{~cm}^{-1}$ found in this last work and which was not observed before. ${ }^{43,44}$ In addition, based on our Raman scattering experiments at high temperature (see below), we were able to show that the asymmetry of the peak at about $150 \mathrm{~cm}^{-1}$ is due to the presence of two Raman-active modes of $\mathrm{A}_{\mathrm{g}}$ and $\mathrm{T}_{\mathrm{g}}$ symmetries, in very good agreement with our DFT calculations (see Tables 3 and 4) and prior lattice dynamics calculations using force constant models ${ }^{49}$ and DFT. ${ }^{47,50}$ Therefore, in the present work, we are able to assign the 8 Raman active modes of $\mathrm{CoSb}_{3}$ for the first time. The full-width at half-maximum (FWHM) $\Delta_{\mathrm{i}}$ vary between $1.3 \mathrm{~cm}^{-1}$ and $3.7 \mathrm{~cm}^{-1}$, which corresponds to relaxation time $\tau_{\mathrm{i}}$ between $1.4 \mathrm{ps}$ and $4.1 \mathrm{ps}$. These values are in good agreement with the relaxation rates of 0.03 to $0.1 \mathrm{THz}$, i. e. $1 \mathrm{~cm}^{-1}$ to $3.3 \mathrm{~cm}^{-1}$, found by $\mathrm{Li}$ and Mingo for the optical phonons between $80 \mathrm{~cm}^{-1}$ and $200 \mathrm{~cm}^{-1}$ by anharmonic ab initio calculations on $\mathrm{CoSb}_{3} .52$

The thermal variation of the mode frequencies is divided into two contributions: ${ }^{75,76}$

$$
\omega_{\mathrm{i}}(\mathrm{T})=\omega_{\mathrm{i}}(\mathrm{T}=0 \mathrm{~K})+\Delta \omega_{\mathrm{i}}^{\mathrm{impl}}+\Delta \omega_{\mathrm{i}}^{\mathrm{expl}}
$$

Where $\Delta \omega_{i}^{i m p l}$ is the implicit contribution taking into account the volume dependence of the mode frequencies and $\Delta \omega_{\mathrm{i}}^{\text {expl }}$ is the explicit contribution determined by the thermal population of the vibrational levels and depending on the anharmonicity.

In the harmonic approximation, the frequencies of the vibrational modes are constants and do not change with volume, pressure or temperature. In the quasi-harmonic approximation, the frequencies of the vibrational modes vary with the volume change and therefore with the temperature and pressure. Thus, in the Grüneisen approximation, this can be expressed as:

$$
\frac{\omega_{i}}{\omega_{i}(T=0 K)}=\left(\frac{\mathrm{V}}{\mathrm{V}_{0}}\right)^{-\gamma_{i}}
$$

with $v_{\mathrm{i}}$ the $\mathrm{i}^{\text {th }}$ mode frequency, $v_{\mathrm{i}}(\mathrm{T}=0 \mathrm{~K})$ the $\mathrm{i}^{\text {th }}$ mode frequency at $\mathrm{T}=0 \mathrm{~K}, \mathrm{~V}$ the cell volume, $\mathrm{V}_{0}$ the cell volume at $\mathrm{T}=0 \mathrm{~K}$ and $\gamma_{\mathrm{i}}$ the $\mathrm{i}^{\text {th }}$ mode Grüneisen parameter. 
One can define the isothermal Grüneisen parameter $\gamma^{\mathrm{T}}$ and the isobaric Grüneisen parameter $\gamma^{\mathrm{P}}$ of the $\mathrm{i}^{\text {th }}$ mode as: ${ }^{73}$

$$
\gamma_{i}^{T}=\left(\frac{\partial \ln \omega_{i}(P, T)}{\partial \ln (V(P, T))}\right)_{T} \text { and } \gamma_{i}^{P}=\left(\frac{\partial \ln \omega_{i}(P, T)}{\partial \ln (V(P, T))}\right)_{P} .
$$

In the isotropic approximation, they can also be expressed as: ${ }^{75,76}$

$$
\gamma_{i}^{T}=B\left(\frac{\partial \ln \omega_{i}}{\partial P}\right)_{T} \text { and } \gamma_{i}^{P}=\frac{-1}{\alpha_{V}}\left(\frac{\partial \ln \omega_{i}}{\partial T}\right)_{P}
$$

with $\mathrm{B}$ being the bulk modulus and $\alpha_{V}$ being the volume thermal expansion.

The thermal variation of the frequency can be determined as: ${ }^{75,76}$

$$
\left(\frac{\partial \omega_{i}}{\partial T}\right)_{P}=-B \alpha_{V}\left(\frac{\partial \omega_{i}}{\partial P}\right)_{T}+\left(\frac{\partial \omega_{i}}{\partial T}\right)_{V}
$$

One can express this equation as: ${ }^{76}$

$$
\gamma_{i}^{P}=\gamma_{i}^{T}+\gamma_{i}^{V}
$$

with $\gamma_{i}^{V}=\frac{-1}{\alpha_{V}}\left(\frac{\partial \ln \omega_{i}}{\partial T}\right)_{V}=-B\left(\frac{\partial \ln \omega_{i}}{\partial P}\right)_{V}$.

Based on Raman scattering experiments under high pressure, one can determine the isothermal Grüneisen parameters $\gamma_{i}^{T}$ and by Raman experiment as a function of temperature, one can determine the isobaric Grüneisen parameters $\gamma_{i}^{P}$. If the quasi-harmonic approximation can be strictly applied, $\gamma_{i}^{V}=0$ and $\gamma_{i}^{P}=\gamma_{i}^{T}$. Therefore, in the general case, $\gamma_{i}^{V}$ is a measure of the anharmonic contribution to the frequency shift, i. e. the explicit effect, whereas $\gamma_{i}^{T}$ corresponds to the volume contribution, i. e. the implicit effect. One can thus define the implicit fraction $\eta_{\mathrm{i}}=\gamma_{i}^{T} / \gamma_{i}^{P} \cdot{ }^{76}$

We have performed Raman scattering experiments to study the self-intercalation of antimony under high pressure as reported using X-ray diffraction by prior studies ${ }^{60-65}$ and to determine the Grüneisen parameters $\gamma_{i}^{T}$ of the different Raman-active modes. As the experiments have been performed on a polycrystalline sample the Raman spectra of which exhibit larger FWHM values. We are therefore not able to distinguish neither the two Raman-active modes around $150 \mathrm{~cm}^{-1}$ nor the two Raman modes around $175 \mathrm{~cm}^{-1}$. Unfortunately, we were not able to observe the $\mathrm{T}_{\mathrm{g}}$ Raman-active mode at about $80 \mathrm{~cm}^{-}$ ${ }^{1}$. The Raman spectra as function of pressure are shown in Fig. 2 for two different runs. Because of the presence of antimony in our polycrystalline sample, one can ask if our Raman spectra of the 
polycrystalline samples under pressure are contaminated by the signal of antimony. In the Raman signal of antimony, there are two intense peaks at $112.5-115 \mathrm{~cm}^{-1}$ and $150-153 \mathrm{~cm}^{-1} 43,77$ and H. Olijnyk et al have shown that their frequency positions decrease significantly with increasing pressure, ${ }^{77}$ in contrast with our results where the frequency positions of all the Raman modes increase significantly with increasing pressure. This means that there is no antimony in the zone of the samples studied in our experiments. At $27 \mathrm{GPa}$, the Raman peaks are suddenly broadened. This spectral change is thought to be due to a structure change. Since the spectral shapes of the high pressure phase are similar to those of filled skutterudite, ${ }^{45}$ the phase change can be interpreted according to self insertion of Sb proposed by Kraemer et al. ${ }^{59,60}$ This structure change at $27 \mathrm{GPa}$ is found to be irreversible because after pressurization to $36 \mathrm{GPa}$ the spectrum is not recovered when decompressing down to room pressure (see Supplementary Information). We obtained a spectrum with two broad peaks at $150 \mathrm{~cm}^{-1}$ and $175 \mathrm{~cm}^{-1}$. We also note that there was an irreversibility of the volume change after decompression in the XRD experiments done by Kramer et al ${ }^{60}$ and Matsui et al. ${ }^{61,63}$ Using DFT calculations, we have checked that moving one $\mathrm{Sb}$ atom from the cage framework to the (2a) site is unstable both at 0 and $30 \mathrm{GPa}$. This suggests that the structure change could be just a structural instability. The Sb-vacancies and Sb-guests could be kinetically trapped after decompression. However, further studies are required to confirm this scenario.

In order to understand the effect of the intercalation of $\mathrm{Sb}$ guest atom on the (2a) site on the lattice dynamics, we have performed DFT calculations of $\mathrm{SbCo}_{4} \mathrm{Sb}_{12}$ at $0 \mathrm{GPa}$ and $30 \mathrm{GPa}$. The phonon dispersion curves and phonon density of states of $\mathrm{SbCo}_{4} \mathrm{Sb}_{12}$ and of $\mathrm{CoSb}_{3}$ (for comparison) at $0 \mathrm{GPa}$ are presented in Figs 3 and 4, respectively. We list the $\Gamma$ point frequencies of $\mathrm{SbCo}_{4} \mathrm{Sb}_{12}$ in Table 5. The incorporation of $\mathrm{Sb}$ guest atom downshifts significantly the vibration modes. This is mainly due to the expansion of the lattice by the intercalation of the $\mathrm{Sb}$ guest atom. A similar behaviour has been observed in Raman scattering experiments of $\mathrm{Sn}_{\mathrm{x}} \mathrm{Co}_{4} \mathrm{Sb}_{12}$, however, with much lower magnitude. ${ }^{45}$ As expected, we also find that there is an additional $\mathrm{T}_{\mathrm{u}}$ infrared-active mode due to the $\mathrm{Sb}$ guest atom at the (2a) site at $35.8 \mathrm{~cm}^{-1}$. We note that the characteristic frequencies of vibrations between 30 and $50 \mathrm{~cm}^{-1}$ are connected to both the $\mathrm{Sb}$ guest atom and the $\mathrm{Sb}$ atoms of the cage framework. 
We have calculated the atomic displacement parameters (ADPs) of the different atoms (see Supplementary Information).As expected, we find a much larger ADP for the Sb guest atoms located at the (2a) site. At $300 \mathrm{~K}$, we find $\mathrm{B}_{\text {iso }}(\mathrm{Co})=0.42 \AA^{2}, \mathrm{~B}_{\text {iso }}(\mathrm{Sb})=0.67 \AA^{2}$ and $\mathrm{B}_{\text {iso }}\left(\mathrm{Sb}_{\text {guest }}\right)=2.02 \AA^{2}$. These values are in reasonable agreement with the values found for $\mathrm{Sb}_{0.8} \mathrm{Co}_{4} \mathrm{Sb}_{11.2}: \mathrm{B}_{\text {iso }}(\mathrm{Co})=0.8(6) \AA^{2}$, $\mathrm{B}_{\text {iso }}(\mathrm{Sb})=0.8(7) \AA^{2}$ and $\mathrm{B}_{\text {iso }}\left(\mathrm{Sb}_{\text {guest }}\right)=2.2(3) \AA^{2} .{ }^{65}$ Upon increasing the pressure to $30 \mathrm{GPa}$, all vibrational modes have positive frequencies, indicating that $\mathrm{SbCo}_{4} \mathrm{Sb}_{12}$ is a stable structure. At this pressure, the atom-projected phonon DOS of the Sb guest atoms is greatly upshifted up to $65 \mathrm{~cm}^{-1}$ and the low energy vibrational modes are dominated by the $\mathrm{Sb}$ atoms of the framework up to $100 \mathrm{~cm}^{-1}$ (see Supplementary Information). As the $\mathrm{Sb}$ guest atoms give an additional IR $\mathrm{T}_{\mathrm{u}}$ mode, we cannot see it in Raman experiments and our calculations predict that the signature of the Sb intercalation in the Raman scattering should be the downshift of the Raman-active mode after decompression down to room pressure. However, because of the large broadening of the peak, this is difficult to confirm.

Fig. 5 shows the pressure dependence of Raman frequencies of $\mathrm{CoSb}_{3}$. The error of the Raman frequencies are within the size of the symbols. The isothermal mode Grüneisen parameters $\gamma_{i}^{T}$ are listed in Table 3. The pressure dependence of the cell volume, which is needed for obtaining the $\gamma_{i}^{T}$, was taken from Kraemer et al. ${ }^{60}$ We report the isothermal mode Grüneisen constants $\gamma_{i}^{T}$ from the DFT calculations in Tables 3 and 4. There is a good correspondence with the experimental values. The three lowest energy vibrational modes have low $\gamma_{i}^{T}$ values, which are less than 1 . These values can be compared to the thermodynamic Grüneisen parameter $\Gamma=3 \alpha \mathrm{V} \mathrm{B} / \mathrm{C}_{\mathrm{P}}$, where $\alpha$ is the linear thermal expansion, $\mathrm{V}$ the molar volume and $\mathrm{C}_{\mathrm{P}}$ the heat capacity. ${ }^{78}$ Caillat et al reported that $\alpha=6.36 \mathrm{MK}^{-1}$ and that the Grüneisen parameter $\Gamma=0.952 .{ }^{79}$ However, two recent works reported a thermal expansion that was $50 \%$ larger. ${ }^{80,81}$ Using $\alpha=9.9 \mathrm{MK}^{-1}$ found by Hanus et al, ${ }^{81}$ one derives $\Gamma=1.482$. This value is intermediate between the different mode Grüneisen parameters $\gamma_{i}^{T}$ found above.

We show the Raman spectra of single-crystal $\mathrm{CoSb}_{3}$ as a function of temperature in Fig. 6. Note that besides the downshift of the different peaks, the peak at about $150 \mathrm{~cm}^{-1}$ splits into two peaks with increasing temperature. This shows that the slightly asymmetric peak at about $150 \mathrm{~cm}^{-1}$ has two different components (see above for more detailed explanations). Conversely, the two peaks at about $175 \mathrm{~cm}^{-1}$ 
merge into one asymmetric peak with increasing temperature. We report the thermal variation of the positions of the different Raman-active modes in Fig. 7(a). The error of the mode positions are within the size of the symbols. As the mode positions vary linearly with the temperature from room temperature up to $400^{\circ} \mathrm{C}$ (except for the two highest energy $\mathrm{T}_{\mathrm{g}}$ modes), one can determine the isobaric Grüneisen parameters $\gamma_{i}^{P}$ from the slope obtained by linear fitting of the thermal variation of the frequencies and with the knowledge of the thermal expansion obtained by Hanus et al. ${ }^{81}$ From the knowledge of both $\gamma_{i}^{P}$ and $\gamma_{i}^{T}$, one can obtain $\gamma_{i}^{V}$ and the implicit ratio $\eta_{\mathrm{i}}$ of each Raman-active mode. The results are given in Table 3. For the lowest energy $\mathrm{A}_{\mathrm{g}}$ and $\mathrm{E}_{\mathrm{g}}$ modes and for the $\mathrm{T}_{\mathrm{g}}$ mode at about $108 \mathrm{~cm}^{-1}$, the ratio $\eta_{\mathrm{i}}$ is about 0.5 , which means that the implicit volume contribution and the explicit anharmonic contribution are more or less the same. However, for the two highest energy modes, the ratio $\eta_{\mathrm{i}}$ is larger than 0.5 , which means that the implicit volume contribution is the dominant component. When $\eta_{\mathrm{i}}$ is smaller than or about 0.5 , the bonding is covalent, like in $\mathrm{ZnS}$ or semiconducting $\mathrm{Mg}_{2} \mathrm{X}(\mathrm{X}=\mathrm{Si}, \mathrm{Ge}, \mathrm{Sn})$ and when it is significantly larger than 0.5 , the bonding is ionic. ${ }^{82-84}$ In the case of $\mathrm{CoSb}_{3}$, we have both cases, which means that the bonding is iono-covalent.

We show the thermal variation of the FWHM $\Delta_{\mathrm{i}}$ of the lowest $\mathrm{E}_{\mathrm{g}}$ and the highest $\mathrm{A}_{\mathrm{g}}$ mode in Fig. 7(b). We notice a clearly increasing trend with increasing temperature. It is difficult to deconvolute the two modes at $150 \mathrm{~cm}^{-1}$ and $175 \mathrm{~cm}^{-1}$ and to derive reliable FWHM $\Delta_{\mathrm{i}}$ without large errors. The same holds for the peak of the lowest energy $\mathrm{T}_{\mathrm{g}}$ mode due to its very low intensity.

The FWMH $\Delta_{\mathrm{i}}$ can be expressed as function of the residual term $\Delta(0)$ of the 3 phonons interaction term $\Delta_{3}$ and of the 4 phonons interaction term $\Delta_{4}:{ }^{75,76,85}$

$$
\Delta_{\mathrm{i}}=\Delta(\mathrm{T}=0 \mathrm{~K})+\Delta_{3}+\Delta_{4}
$$

With the term $\Delta(\mathrm{T}=0 \mathrm{~K})$ being constant and: ${ }^{75,76,85}$

$$
\Delta_{3}=A\left(1+\frac{2}{e^{x}-1}\right) \text { and } \Delta_{4}=B\left[1+\frac{3}{e^{y}-1}+\frac{3}{\left(e^{y}-1\right)^{2}}\right]
$$

with $x=\frac{\hbar \omega_{i}}{2 k_{B} T}$ and $y=\frac{\hbar \omega_{i}}{3 k_{B} T}$.

The experimental data were modeled using these equations in Figure 7 (b). 


\section{Conclusion}

We have reported a study of the anharmonicity of the unfilled skutterudite $\mathrm{CoSb}_{3}$ from the pressure and temperature dependence of the Raman-active modes. Based on the temperature dependence, we were able to carry out the full assignment of the Raman-active modes of $\mathrm{CoSb}_{3}$ for the first time. We have observed a significant broadening and irreversible change of the Raman spectrum above $27 \mathrm{GPa}$. This was attributed to the self-insertion of antimony atoms in the cages, which was reported in some prior

structural studies of $\mathrm{CoSb}_{3}$ under high pressure. ${ }^{60-63}$ We reported the lattice dynamics of $\mathrm{SbCo}_{4} \mathrm{Sb}_{12}$ by DFT calculations and find a very low energy optical mode due to the formation of hybrid modes of the guest atoms with the host network. We reported the isothermal Grüneisen parameters of the Ramanactive modes that are as large as 2 for the highest energy modes. From the analysis of the thermal and pressure dependence of the Raman-active modes, we found that the implicit volume contribution is the dominant contribution for the highest energy Raman-active modes, whereas both implicit volume contribution and explicit anharmonic contribution have same magnitudes for the other Raman-active modes.

\section{Associated content}

\section{A. Supplementary informations}

Raman spectra of $\mathrm{CoSb}_{3}$ under decompression, calculations of the atomic potential of silicon in $\mathrm{Ba}_{24} \mathrm{Si}_{100}$, the calculations of the electronic density of states of $\mathrm{CoSb}_{3}$ and $\mathrm{SbCo}_{4} \mathrm{Sb}_{12}$ at $0 \mathrm{GPa}$, the calculations of the atomic displacements parameters of $\mathrm{SbCo}_{4} \mathrm{Sb}_{12}$ at $0 \mathrm{GPa}$, the calculations of the phonon dispersion curves and density of states $\mathrm{SbCo}_{4} \mathrm{Sb}_{12}$ at $30 \mathrm{GPa}$.

\section{Acknowledgement}

We thank D. Granier for single-crystal X-ray diffraction measurements. 


\section{References}

${ }^{1}$ Oftedal, I., XXXIII. Die kristallstruktur von skutterudit and speiskobalt-chloanthit. Z. Krist. 1928, 66, 517-546.

${ }^{2}$ Rosenqvist, T., Magnetic and crystallographic studies of the higher antimonies of iron, cobalt and nickel. Acta Met. 1953, 1, 761-763.

${ }^{3}$ Zhuravlev, N. N.; Zdanov, G. S., X-ray determination of the structure of $\mathrm{CoSb}_{3}, \mathrm{RhSb}_{3}$ and $\mathrm{IrSb}_{3}$. Kristallografiya 1956, 1, 509-513.

${ }^{4}$ Kjekshus, A.; Pedersen, G., Crystal structures of IrAs 3 and IrSb ${ }_{3}$. Acta Cryst. 1961, 14, 1065-1070.

${ }^{5}$ Kjekshus, A.; Nicholson, D. G.; Rakke, T., Compounds with the skutterudite type crystal structure. I. On Oftedal's relation. Acta Chem. Scand. 1974, 27, 1307-1314.

${ }^{6}$ Kjekshus, A.; Rakke, T., Compounds with the skutterudite type crystal structure. III. Structural data for arsenides and antimonides. Acta Chem. Scand. 1974, 28, 99-103.

${ }^{7}$ Uher, C., Skutterudites: Prospective novel thermoelectrics. Semicond. Semimet. 2001, 69, 139-253.

${ }^{8}$ Jeitschko, W.; Braun, D. J., $\mathrm{LaFe}_{4} \mathrm{P}_{12}$ with filled $\mathrm{CoAs}_{3}$-type structure and isotypic lanthanoidtransition metal polyphosphide. Acta Cryst. 1977, B33, 3401-3406.

${ }^{9}$ Braun, D. J.; Jeitschko, W., Preparation and structural investigations of antimonides with the $\mathrm{LaFe}_{4} \mathrm{P}_{12}$ structure. J. Less-Com. Met. 1980, 72, 147-156.

${ }^{10}$ Dudkin, L. D.; Abrikosov, N. K., On the doping of the semiconductor compound $\mathrm{CoSb}_{3}$. Sov. Phys. Solid State 1959, 1, 126-133.

${ }^{11}$ Hulliger, F., Semiconducting compounds with skutterudite structure. Helvetica Phys. Acta 1961, 34, 782-786.

${ }^{12}$ Ackermann, J.; Wold, A., The preparation and characterization of the cobalt skutterudites $\mathrm{CoP}_{3}, \mathrm{CoAs}_{3}$ and $\mathrm{CoSb}_{3}$. J. Phys. Chem. Solids 1977, 38, 1013-1016.

${ }^{13}$ Lutz, H. D.; Kliche, G., IR-spektroskopische untersuchungen an verbindungen des skutterudit-typs $\mathrm{MX}_{3}(\mathrm{M}=\mathrm{Co}, \mathrm{Rh}, \mathrm{Ir} ; \mathrm{X}=\mathrm{P}, \mathrm{As}, \mathrm{Sb})$. Z. Anorg. Allg. Chem. 1981, 480, 105-116.

${ }^{14}$ Lutz, H. D.; Kliche, G., Far-infrared reflection spectra, optical and dielectric constants, effective charges, and lattice dynamics of the skutterudites $\mathrm{CoP}_{3}, \mathrm{CoAs}_{3}$ and $\mathrm{CoSb}_{3}$. Phys. Stat. Sol. (b) 1982, $112,549-557$. 
${ }^{15}$ Kliche, G.; Lutz, H. D., Temperature dependence of the FIR reflection spectra of the skutterudites $\mathrm{CoAs}_{3}$ and $\mathrm{CoSb}_{3}$. Infrared Phys. 1984, 24, 171-177.

${ }^{16}$ Schmidt, T.; Kliche, G.; Lutz, H. D., Structure refinements of skutterudite-type cobalt triantimonide $\mathrm{CoSb}_{3}$. Acta Cryst. 1987, C43, 1678-1679.

${ }^{17}$ Caillat, T.; Borshchevsky, A.; Fleurial, J.-P., Phase diagram of the Ir-Sb system on the antimony-rich part. J. Alloys Compds. 1993, 199, 207-210.

${ }^{18}$ Slack, G. A.; Tsoukala, V. G., Some properties of semiconducting $\mathrm{IrSb}_{3}$. J. Appl. Phys. 1994, 76, $1665-1671$.

${ }^{19}$ Morelli, D. T.; Caillat, T.; Fleurial, J.-P.; Borshchevsky, A.; Vandersande, J.; Chen, B.; Uher, C., Low-temperature transport properties of p-type $\mathrm{CoSb}_{3}$. Phys. Rev. B 1995, 51, 9622-9628.

${ }^{20}$ Sharp, J. W.; Jones, E. C.; Williams, R. K.; Martin, P. M.; Sales, B. C., Thermoelectric properties of $\mathrm{CoSb}_{3}$ and related alloys. J. Appl. Phys. 1995, 78, 1013-1018.

${ }^{21}$ Mandrus, D.; Migliori, A.; Darling, T. W.; Hundley, M. F.; Peterson, E. J.; Thompson, J. D., Electronic transport in lightly doped $\mathrm{CoSb}_{3}$. Phys. Rev. B 1995, 52, 4926-4931.

${ }^{22}$ Slack, G. A., CRC Handbook of Thermoelectricity, CRC Press LLC, ch. 34, 1995.

${ }^{23}$ Sales, B. C.; Mandrus, D.; Williams, R. K., Filled skutterudite antimonides: A new class of Thermoelectric Materials. Science 1996, 272, 1325-1328 (1996).

${ }^{24}$ Fleurial, J.-P.; Borshchevsky, A.; Caillat, T., Morelli, D. T.; Meisner, G. P., High Figure of Merit in Ce-Filled Skutterudites. Proc. 15 ${ }^{\text {th }}$ Internat. Conf. Thermoel., IEEE ed., 1996, 91-95.

${ }^{25}$ Mahan, G. D., Good Thermoelectrics. Solid State Phys. 1997, 51, 81-157.

${ }^{26}$ Shi, X.; Yang, J.; Salvador, J. R.; Chi, M.; Cho, J. Y.; Wang, H.; Bai, S.; Yang, J.; Zhang, W.; Chen, L., .Multiple-Filled Skutterudites: High Thermoelectric Figure of Merit through Separately Optimizing Electrical and Thermal Transports. J. Am. Chem. Soc. 2011, 133, 7837-7846.

${ }^{27}$ Rogl, G.; Grytsiv, A.; Rogl, P.; Peranio, N.; Bauer, E.; Zehetbauer, M.; Eibl, O., n-Type skutterudites $(\mathrm{R}, \mathrm{Ba}, \mathrm{Yb})_{\mathrm{y}} \mathrm{Co}_{4} \mathrm{Sb}_{12}(\mathrm{R}=\mathrm{Sr}, \mathrm{La}, \mathrm{Mm}, \mathrm{DD}, \mathrm{SrMm}, \mathrm{SrDD})$ approaching $\mathrm{ZT} \approx 2.0$. Acta Mater. 2014, 63, $30-43$.

${ }^{28}$ Liang, T.; Su, X.; Yan, Y.; Zheng, G.; She, X.; You, Y.; Uher, C.; Kanatzidis, M. G.; Tang, X., Panoscopic approach for high-performance Te-doped skutterudite. NPG Asia Mater. 2017, 9, e352. 
${ }^{29}$ Khan, A. U.; Kobayashi, K.; Tang, D.-M.; Yamauchi, Y.; Hasegawa, K.; Mitome, M.; Xue, Y.; Jiang, B.; Tsuchiya, K.; Golberg, D.; Bando, Y.; Mori, T., Nano-micro-porous skutterudites with $100 \%$ enhancement in ZT for high performance thermoelectricity. Nano Energy 2017, 31, 152-159.

${ }^{30}$ Singh, D. J.; Pickett, W. E., Skutterudite antimonides: Quasilinear bands and unusual transport. Phys. Rev. B 1994, 50, 11235-11238.

${ }^{31}$ Sofo, J. O.; Mahan, G. D., Electronic structure of $\mathrm{CoSb}_{3}$ : A narrow-band-gap semiconductor. Phys. Rev. B 1998, 58, 15620-15623.

${ }^{32}$ Smith, J. C.; Banerjee, S.; Pardo, V.; Pickett, W. E., Dirac point degenerate with massive bands at a topological quantum critical point. Phys. Rev. Lett. 2011, 106, 056401.

${ }^{33}$ Pardo, V.; Smith, J. C.; Pickett, W. E., Linear bands, zero-momentum Weyl semimetal, and topological transition in skutterudite-structure pnictides. Phys. Rev. B 85, 214531 (2012).

${ }^{34}$ Tang, Y.; Gibbs, Z. M.; Agapito, L. A.; Li, G.; Kim, H.-S.; Nardelli, M. B.; Curtarolo, S.; Snyder, G. J., Convergence of multi-valley bands as the electronic origin of high thermoelectric performance in $\mathrm{CoSb}_{3}$ skutterudites. Nat. Mater. 2015, 14, 1223-1229.

${ }^{35}$ Errandonea, D. ; Martinez-Garcia, D. ; Segura, A. ; Haines, J. ; Machado-Charry, E. ; Canadell, E. ; Chervin, J. C. ; Chevy, A., High-pressure electronic structure and phase transitions in monoclinic InSe : X-ray diffraction, Raman spectroscopy, and density functional theory. Phys. Rev. B 2008, 77, 045208. ${ }^{36}$ Ruiz-Fertes, J. ; Friedrich, A. ; Errandonea, D. ; Segura, A. ; Morgenroth, W. ; Rodriguez-Hernandez, P. ; Munoz, A. ; Meng, Y., Optical and structural studiy of the pressure-induced phase transition of CdWO 4 . Phys. Rev. B 2017, 95, 174105.

${ }^{37}$ Khan, B.; Rahnamaye Aliabad, H. A.; Saifullah; Jalali-Asadabadi, S.; Khan, I.; Ahmad, I., Electronic band structures of binary skutterudites. J. Alloys Compds 2015, 647, 364-369.

${ }^{38}$ Koza, M. M.; Johnson, M. R.; Viennois, R.; Mutka, H.; Girard, L.; Ravot, D., Breakdown of phonon glass paradigm in La- and Ce-filled $\mathrm{Fe}_{4} \mathrm{Sb}_{12}$ skutterudites. Nat. Mater. 2008, 7, 805-810.

${ }^{39}$ Bernstein, N.; Feldman, J. L.; Singh, D. J., Calculations of dynamical properties of skutterudites: Thermal conductivity, thermal expansivity, and atomic mean-square displacement. Phys. Rev. B 2010, $81,134301$. 
${ }^{40}$ Li, W.; Mingo, N., Thermal conductivity of fully filled skutterudites: Role of the filler. Phys. Rev. B 2014, $89,184304$.

${ }^{41} \mathrm{Li}$, W.; Mingo, N., Ultralow lattice thermal conductivity of the fully filled skutterudite $\mathrm{YbFe}_{4} \mathrm{Sb}_{12}$ due to the flat avoided-crossing filler modes. Phys. Rev. B 2015, 91, 144304.

${ }^{42}$ Koza, M. M.; Boehm, M.; Sischka, E.; Schnelle, W.; Mutka, H.; Leithe-Jasper, A., Low-energy phonon dispersion in $\mathrm{LaFe}_{4} \mathrm{Sb}_{12}$. Phys. Rev. B 91, 014305 (2015).

${ }^{43}$ Nolas, G. S.; Slack, G. A.; Caillat, T.; Meisner, G. P., Raman scattering study of antimony based skutterudites. J. Appl. Phys. 1996, 79, 2622-2626.

${ }^{44}$ Nolas, G. S.; Kendziora, C. A., Raman spectroscopy investigation of lanthanide-filled and unfilled skutterudites. Phys. Rev. B 1999, 59, 6189-6192.

${ }^{45}$ Nolas, G. S.; Kendziora, C. A.; Takizawa, H., Polarized Raman-scattering study of Ge- and Sn-filled $\mathrm{CoSb}_{3}$. J. Appl. Phys. 2003, 94, 7440-7444.

${ }^{46}$ Feldman, J. L.; Dai, P.; Enck, T.; Sales, B. C.; Mandrus, D.; Singh, D. J., Lattice vibrations in $\mathrm{La}(\mathrm{Ce}) \mathrm{Fe}_{4} \mathrm{Sb}_{12}$ and $\mathrm{CoSb}_{3}$ : Inelastic neutron scattering and theory. Phys. Rev. B 2006, 73, 014306.

${ }^{47}$ Rotter, M.; Rogl, P.; Grytsiv, A.; Wolf, W.; Krisch, M.; Mirone, A., Lattice dynamics of skutterudites: Inelastic X-ray scattering on $\mathrm{CoSb}_{3}$. Phys. Rev. B 2008, 77, 144301.

${ }^{48}$ Wille, H.-C.; Hermann, R. P.; Sergueev, I.; Leupold, O.; van der Linden, P.; Sales, B. C.; Grandjean, F.; Long, G. J.; Rüffer, R.; Shvyd'ko, Y. V., Antimony vibrations in skutterudites probed by ${ }^{121} \mathrm{Sb}$ nuclear inelastic scattering. Phys. Rev. B 2007, 76, 140301(R).

${ }^{49}$ Feldman, J. L.; Singh, D. J., Lattice dynamics of skutterudites: First-principles and model calculations for $\mathrm{CoSb}_{3}$. Phys. Rev. B 1996, 53, 6273-6282.

${ }^{50}$ Ghosez, P.; Veithen, M., First-principles study of filled and unfilled antimony skutterudites. J. Phys.: Cond. Mat. 2007, 19, 096002.

${ }^{51}$ Huang, B.; Kaviany, M., Filler reduced phonon conductivity of thermoelectrics skutterudites: Ab initio calculations and molecular dynamics simulations. Acta Mater. 2010, 58, 4516-4526.

${ }^{52}$ Li, W.; Mingo, N., Lattice dynamics and thermal conductivity of skutterudites $\mathrm{CoSb}_{3}$ and $\mathrm{IrSb}_{3}$ from first principles: Why $\mathrm{IrSb}_{3}$ is a better thermal conductor than $\mathrm{CoSb}_{3}$. Phys. Rev. B 2014, 90, 094302. 
${ }^{53}$ Guo, R.; Wang, X.; Huang, B., Thermal conductivity of skutterudite $\mathrm{CoSb}_{3}$ from first principles: Substitution and nanoengineering effects. Scient. Rep. 2015, 5, 7806.

${ }^{54}$ Tse, J. S.; English, N. J.; Yin, K.; Iitaka, T., Thermal conductivity of solids from first-principles molecular dynamics calculations. J. Phys. Chem. C 2018, 122, 10682-10690.

${ }^{55}$ Niwa, K.; Nomichi, D.; Hasegawa, M.; Okada, T.; Yagi, T.; Kikegawa, T., Compression behaviors of binary skutterudite $\mathrm{CoP}_{3}$ in noble gases up to $40 \mathrm{GPa}$ at room temperature. Inorg. Chem. 2011, 50, 32813285.

${ }^{56}$ Martinotto, A. L.; Gava, V.; Perottoni, C. A., Influence of pressure and transition metal $(\mathrm{T}=\mathrm{Fe}, \mathrm{Co})$ on the lanthanum bare frequency in $\mathrm{LaT}_{4} \mathrm{Sb}_{12}$. Phys. Rev. B 2010, 81, 104112.

${ }^{57}$ Yang, X.; Dai, Z.; Zhao, Y.; Niu, W.; Liu, J.; Meng, S., Pressure induced excellent thermoelectric behavior in skutterudites $\mathrm{CoSb}_{3}$ and $\mathrm{IrSb}_{3}$. Phys. Chem. Chem. Phys. 2019, 21, 851-858.

${ }^{58}$ Shirotani, I.; Noro, T.; Hayashi, J.; Sekine, C.; Giri, R.; Kikegawa, T., X-ray study with synchrotron radiation for P-and Sb-based skutterudite compounds at high pressures. J. Phys.: Condens. Matter 2004, $16,7853-7862$.

${ }^{59}$ Kraemer, A. C.; Perottoni, C. A.; da Jornada, J. A. H., Isothermal equation of state for the skutterudites $\mathrm{CoSb}_{3}$ and $\mathrm{LaFe}_{3} \mathrm{CoSb}_{12}$. Solid State Commun. 2005, 133, 173-176.

${ }^{60}$ Kraemer, A. C.; Gallas, M. R.; da Jornada, J. A. H.; Perottoni, C. A., Pressure-induced self-insertion reaction in $\mathrm{CoSb}_{3}$. Phys. Rev. B 2007, 75, 024105.

${ }^{61}$ Matsui, K.; Hayashi, J.; Akahira, K.; Ito, K.; Takeda, K.; Sekine, C., Pressure-induced irreversible isosymmetric transition of $\mathrm{TSb}_{3}(\mathrm{~T}=\mathrm{Co}, \mathrm{Rh}$ and Ir). J. Phys.: Conf. Series 2010, 215, 012005.

${ }^{62}$ Matsui, K.; Hayashi, J.; Akahira, K.; Ito, K.; Fukushi, Y.; Takeda, K.; Sekine, C., Structural instability of unfilled skutterudite compounds $\mathrm{TSb}_{3}(\mathrm{~T}=\mathrm{Co}, \mathrm{Rh}$ and $\mathrm{Ir})$ under high pressure. J. Phys.: Conf. Series 2011, 273, 012043.

${ }^{63}$ Matsui, K.; Yamamoto, K.; Kawai, T.; Kawamura, Y.; Hayashi, J.; Takeda, K.; Sekine, C., Structural instability of unfilled skutterudite compounds $\mathrm{MX}_{3}(\mathrm{M}=\mathrm{Co}$, Rh and Ir; $\mathrm{X}=\mathrm{P}$, As and $\mathrm{Sb})$ under high pressure. J. Phys. Soc. Jpn. 2012, 81, 104604.

${ }^{64}$ Miotto, F.; Figueirêdo, C. A.; Ramos, G. R.; Amorim, C. L. G.; Gallas, M. R.; Perottoni, C. A., Antimony disinsertion reaction from $\mathrm{Sb}_{\mathrm{x}} \mathrm{CoSb}_{3-\mathrm{x} .}$ J. Appl. Phys. 2011, 110, 043529. 
${ }^{65}$ Figueirêdo, C. A.; Gallas, M. R.; Zorzi, J. E.; Perottoni, C. A., Synthesis and thermoelectric properties of $\mathrm{Sb}_{0.2} \mathrm{CoSb}_{2.8}$ skutterudite. J. Alloys Compds 2014, 598, 266-271.

${ }^{66}$ Errandonea, D. ; Boehler, R. ; Japel, S. ; Mezouar, M. ; Benedetti, L. R., Structural transformation of compressed solid Ar : An x-ray diffraction study to 114 GPa. Phys. Rev. B 2006, 73, 092106.

${ }^{67}$ Piermiarini, G. J. ; Block, S. ; Barnett, J. D. ; Forman, R. A., Calibration of the pressure dependence of the $\mathrm{R}_{1}$ ruby fluorescence line to 195 kbars, J. Appl. Phys. 1975, 46, 2774-2780.

${ }^{68}$ Kresse, G.; Joubert, D., From ultrasoft pseudopotentials to the projector augmented-wave method. Phys. Rev. B 1999, 59, 1758-1775.

${ }^{69}$ Perdew, J. P.; Burke, K.; Erzenhof, M., Generalized gradient approximation made simple. Phys. Rev. Lett. 1996, 77, 3865-3868.

${ }^{70}$ Schmøkel, M. T.; Bjerg, L.; Larsen, F. K.; Overgaard, J.; Cenedese, S.; Christensen, M.; Madsen, G. K. H.; Gatti, C.; Nishibori, E.; Sugimoto, K.; Takata, M.; Iversen, B. B., Comparative study of X-ray charge-density data on $\mathrm{CoSb}_{3}$. Acta Cryst. 2013, A69, 570-582.

${ }^{71}$ Vinet, P.; Rose, J. H.; Ferrante, J.; Smith, J. R., Universal features of the equation of states of solids. J. Phys.: Condens. Matter 1989, 1, 1941.

${ }^{72}$ Parlinski, K.; Li, Z.-Q.; Kawazoe, Y., First-principles determination of the soft mode in cubic $\mathrm{ZrO}_{2}$. Phys. Rev. Lett. 1997, 78, 4063-4066.

${ }^{73}$ Cazorla, C. ; McLeod, S. G. ; Errandonea, D. ; Munro, K. A. ; McMahon, M. I. ; Popescu, C., Thallium under extreme compression. J. Phys.: Condens. Matter 2016, 28, 445401.

${ }^{74}$ Häussermann, U. ; Söderberg, Norrestam, R., Comparative study of the high-pressure behavior of As, Sb, and Bi. J. Am. Chem. Soc. 2002, 124, 15359-15367.

${ }^{75}$ Lucazeau, G., Effect of pressure and temperature on Raman spectra of solids: anharmonicity. $J$. Raman Spectrosc. 2003, 34, 478-496.

${ }^{76}$ Liarokiapis, E. ; Anastassakis, E. ; Kourouklis, G. A., Raman study of the phonon anharmonicity in $\mathrm{LaF}_{3}$. Phys. Rev. B 1985, 32, 8346-8355.

${ }^{77}$ Olijnyk, H. ; Nakano, S. ; Takemura, K., First- and second order Raman scattering in Sb and Bi at high pressure. Phys. Stat. Sol. (b) 2007, 244, 3572-3582. 
${ }^{78}$ Barron, T. H. K. ; Collins, J. G. ; White, G. K., Thermal expansion of solids at low temperatures. Adv. Phys. 1981, 29, 609-730.

${ }^{79}$ Caillat, T.; Borshchevsky, A.; Fleurial, J.-P., Properties of single-crystalline semiconducting $\mathrm{CoSb}_{3}$. J. Appl. Phys. 1996, 80, 4442-4449.

${ }^{80}$ Rogl, G.; Zhang, L.; Rogl, P.; Falmbigl, M.; Rajs, D.; Kriegisch, M.; Müller, H.; Bauer, E.; Koppensteiner, J.; Schranz, W.; Zehetbauer, M.; Henkie, Z.; Maple, M. B., Thermal expansion of skutterudites. J. Appl. Phys. 2010, 107, 043507.

${ }^{81}$ Hanus, R.; Guo, X.; Tang, Y.; Li, G.; Snyder, G. J.; Zeier, W. G., A Chemical understanding of the band convergence in thermoelectric $\mathrm{CoSb}_{3}$ skutterudites: Influence of electron population local Thermal expansion, and bonding interactions. Chem. Mater. 2017, 29, 1156-1164.

${ }^{82}$ Weinstein, B. A. ; Zallen, R. In Topics in Applied Physics: Light scattering IV; Cardona, M., Güntherodt, G., Eds.; Springer-Verlag: Berlin, Heidelberg, 1984; Vol. 8, pp. 463-527.

${ }^{83}$ Zallen, R.; Slade, M. L., Influence of pressure and temperature on phononsin molecular chalcogenides: Crystalline $\mathrm{As}_{4} \mathrm{~S}_{4}$ and $\mathrm{S}_{4} \mathrm{~N}_{4}$. Phys. Rev. B 1978, 18, 5775-5798.

${ }^{84}$ Raptis, Y. S. ; Kourouklis, G. A. ; Anastassakis, E. ; Haro-Poniatowski, E. ; Balkanski, M., Anharmonic effects in $\mathrm{Mg}_{2} \mathrm{X}(\mathrm{X}=\mathrm{Si}, \mathrm{Ge}, \mathrm{Sn})$ compounds studied by Raman spectroscopy. J. Phys. (Paris) 1987, 48, 239-245.

${ }^{85}$ Balkanski, M. ; Wallis, R. F. ; Haro, E., Anharmonic effects in light scattering due to optical phonons in silicon. Phys. Rev. B 1983, 28, 1928-1934. 


\section{Table captions}

Table 1 : Atomic positions of $\mathrm{CoSb}_{3}$ from the single-crystal and powder X-ray diffraction experiments and from DFT calculations.

Table 2 : Atomic positions of $\mathrm{SbCo}_{4} \mathrm{Sb}_{12}$ from the DFT calculations.

Table 3 : Eigenenergies (in $\mathrm{cm}^{-1}$ ), FWHM (in $\mathrm{cm}^{-1}$ ), relaxation time (in ps) and Grüneisen parameters of the $\Gamma$ point modes of $\mathrm{CoSb}_{3}$ from the Raman scattering experiments. Eigenenergies (in $\mathrm{cm}^{-1}$ ) and Grüneisen parameters of the $\Gamma$ point Raman active modes of $\mathrm{CoSb}_{3}$ from the DFT calculations.

Table 4 : Eigenenergies (in $\mathrm{cm}^{-1}$ ) and Grüneisen parameters of the $\Gamma$ point modes of $\mathrm{CoSb}_{3}$ from the DFT calculations.

Table 5 : Eigenenergies $\left(\right.$ in $\mathrm{cm}^{-1}$ ) of the $\Gamma$ point modes of $\mathrm{SbCo}_{4} \mathrm{Sb}_{12}$ at $0 \mathrm{GPa}$ and $30 \mathrm{GPa}$ from the DFT calculations. 


\section{Tables}

\begin{tabular}{cccccc}
\hline Atom & site & $\mathrm{x}$ & $\mathrm{y}$ & $\mathrm{z}$ & Comments \\
\hline $\mathrm{Co}$ & $8 \mathrm{c}$ & $1 / 4$ & $1 / 4$ & $1 / 4$ & Experiments and DFT \\
$\mathrm{Sb}$ & $24 \mathrm{~g}$ & 0 & $0.33510(2)$ & $0.15787(2)$ & Single-crystal \\
& & 0 & $0.33485(11)$ & $0.15750(12)$ & Powder \\
& & 0 & 0.333449 & 0.159027 & DFT \\
\hline
\end{tabular}

Table 1

\begin{tabular}{ccccc}
\hline Atom & site & $\mathrm{x}$ & $\mathrm{y}$ & $\mathrm{z}$ \\
\hline $\mathrm{Co}$ & $8 \mathrm{c}$ & $1 / 4$ & $1 / 4$ & $1 / 4$ \\
$\mathrm{Sb}$ & $24 \mathrm{~g}$ & 0 & 0.330514 & 0.15913 \\
$\mathrm{Sb}_{\text {guest }}$ & $2 \mathrm{a}$ & 0 & 0 & 0 \\
\hline
\end{tabular}

Table 2

\begin{tabular}{cccccccccc}
\hline Symmetry & $\begin{array}{c}\omega_{\mathrm{i}}\left(\mathrm{cm}^{-1}\right) \\
\text { exp. }\end{array}$ & $\begin{array}{c}\omega_{\mathrm{i}}\left(\mathrm{cm}^{-1}\right) \\
\text { DFT }\end{array}$ & $\begin{array}{c}\Delta_{\mathrm{i}}\left(\mathrm{cm}^{-1}\right) \\
\text { exp. }\end{array}$ & $\begin{array}{c}\tau_{\mathrm{i}}(\mathrm{ps}) \\
\text { exp. }\end{array}$ & $\begin{array}{c}\gamma_{i}^{T} \\
\text { exp. }\end{array}$ & $\begin{array}{c}\gamma_{i}^{T} \\
\text { DFT }\end{array}$ & $\begin{array}{c}\gamma_{i}^{P} \\
\text { exp. }\end{array}$ & $\begin{array}{c}\gamma_{i}^{V} \\
\text { exp. }\end{array}$ & $\begin{array}{c}\eta_{\mathrm{i}} \\
\text { exp. }\end{array}$ \\
\hline $\mathrm{A}_{\mathrm{g}}$ & 149.5 & 145.1 & 1.3 & 4.1 & 1.85 & 1.89 & 3.24 & 1.39 & 0.57 \\
& 177.8 & 174.3 & 1.9 & 2.8 & 1.64 & 1.68 & 2.34 & 0.7 & 0.7 \\
$\mathrm{E}_{\mathrm{g}}$ & 134 & 126.8 & 2.1 & 2.5 & 1.64 & 1.64 & 3.44 & 1.8 & 0.48 \\
& 185.2 & 179.7 & 2 & 2.65 & 1.87 & 1.8 & 2.45 & 0.58 & 0.76 \\
$\mathrm{~T}_{\mathrm{g}}$ & 81.5 & 80.2 & 3.7 & 1.4 & & 0.3 & & & \\
& 108.4 & 102.4 & 2.5 & 2.1 & 1.28 & 1.23 & 2.41 & 1.13 & 0.53 \\
& 150.6 & 145.5 & 2.7 & 2 & & 1.89 & & & \\
& 174.8 & 171 & 3.7 & 1.4 & & 1.8 & & & \\
\hline
\end{tabular}

Table 3 


\begin{tabular}{ccc}
\hline Symmetry & $\omega_{\mathrm{i}}\left(\mathrm{cm}^{-1}\right)$ & $\gamma_{i}^{T}$ \\
\hline $\mathrm{A}_{\mathrm{g}}$ & 145.1 & 1.89 \\
& 174.3 & 1.68 \\
$\mathrm{E}_{\mathrm{g}}$ & 126.8 & 1.64 \\
& 179.7 & 1.8 \\
$\mathrm{~T}_{\mathrm{g}}$ & 80.2 & 0.3 \\
& 102.4 & 1.23 \\
& 145.5 & 1.89 \\
& 171 & 1.8 \\
$\mathrm{~A}_{\mathrm{u}}$ & 110.4 & 0.44 \\
& 240.6 & 1.84 \\
$\mathrm{E}_{\mathrm{u}}$ & 127.1 & 0.77 \\
& 251.4 & 2.09 \\
$\mathrm{~T}_{\mathrm{u}}$ & 75.8 & 0.75 \\
& 114.7 & 1.29 \\
& 137.6 & 1.58 \\
& 171 & 1.5 \\
& 233.9 & 1.8 \\
& 243.7 & 1.71 \\
& 259.5 & 1.9 \\
\hline
\end{tabular}

Table 4 


\begin{tabular}{|c|c|c|}
\hline Symmetry & $\mathrm{P}=0 \mathrm{GPa}$ & $\mathrm{P}=30 \mathrm{GPa}$ \\
\hline \multirow[t]{2}{*}{$\mathrm{A}_{\mathrm{g}}$} & 133.6 & 203.3 \\
\hline & 162.8 & 226.4 \\
\hline \multirow[t]{2}{*}{$\mathrm{E}_{\mathrm{g}}$} & 103.4 & 169.1 \\
\hline & 163.4 & 235.8 \\
\hline \multirow[t]{4}{*}{$\mathrm{T}_{\mathrm{g}}$} & 67.5 & 77.3 \\
\hline & 98.2 & 124.9 \\
\hline & 138.3 & 198.3 \\
\hline & 164.3 & 231.5 \\
\hline \multirow[t]{2}{*}{$\mathrm{A}_{\mathrm{u}}$} & 103.6 & 110.4 \\
\hline & 228.9 & 331.1 \\
\hline \multirow[t]{2}{*}{$\mathrm{E}_{\mathrm{u}}$} & 118.2 & 137.4 \\
\hline & 237.9 & 353.1 \\
\hline \multirow[t]{8}{*}{$\mathrm{T}_{\mathrm{u}}$} & 35.8 & 64.9 \\
\hline & 74.5 & 117.3 \\
\hline & 101 & 141.3 \\
\hline & 110.1 & 157 \\
\hline & 156.1 & 212.6 \\
\hline & 219.1 & 314.3 \\
\hline & 227.5 & 328.9 \\
\hline & 244.3 & 357.2 \\
\hline
\end{tabular}

Table 5 


\section{Figure captions}

Figure 1: Experimental Raman spectrum of a $\mathrm{CoSb}_{3}$ single crystal at $\mathrm{T}=24{ }^{\circ} \mathrm{C}$.

Figure 2: Evolution of the Raman spectra of $\mathrm{CoSb}_{3}$ upon compression. Two different runs are shown.

Figure 3: Phonon dispersion curves of (a) $\mathrm{CoSb}_{3}$ and (b) $\mathrm{SbCo}_{4} \mathrm{Sb}_{12}$ from DFT calculations.

Figure 4: Total and atom-projected phonon density of states of $\mathrm{SbCo}_{4} \mathrm{Sb}_{12}$ from DFT calculations.

Figure 5: Variation of the frequencies of some Raman-active modes in $\mathrm{CoSb}_{3}$ with pressure. Full circles are the experimental data; open symbols are the DFT data with $\mathrm{T}_{\mathrm{g}}$ symmetry (red circles), $\mathrm{E}_{\mathrm{g}}$ symmetry (blue triangles) and $\mathrm{A}_{\mathrm{g}}$ symmetry (black squares).

Figure 6: Evolution of the Raman spectra modes of $\mathrm{CoSb}_{3}$ with temperature.

Figure 7: (a) Variation of the frequencies of the Raman-active modes in $\mathrm{CoSb}_{3}$ with temperature. Mode symmetries are given in the figure. (b) Variation of the FWHM of the Raman-active $\mathrm{E}_{\mathrm{g}}$ modes in $\mathrm{CoSb}_{3}$ with temperature. Experimental data are represented as symbols, calculations with 3 phonon and 4 phonon interactions as solid lines. 
Figures

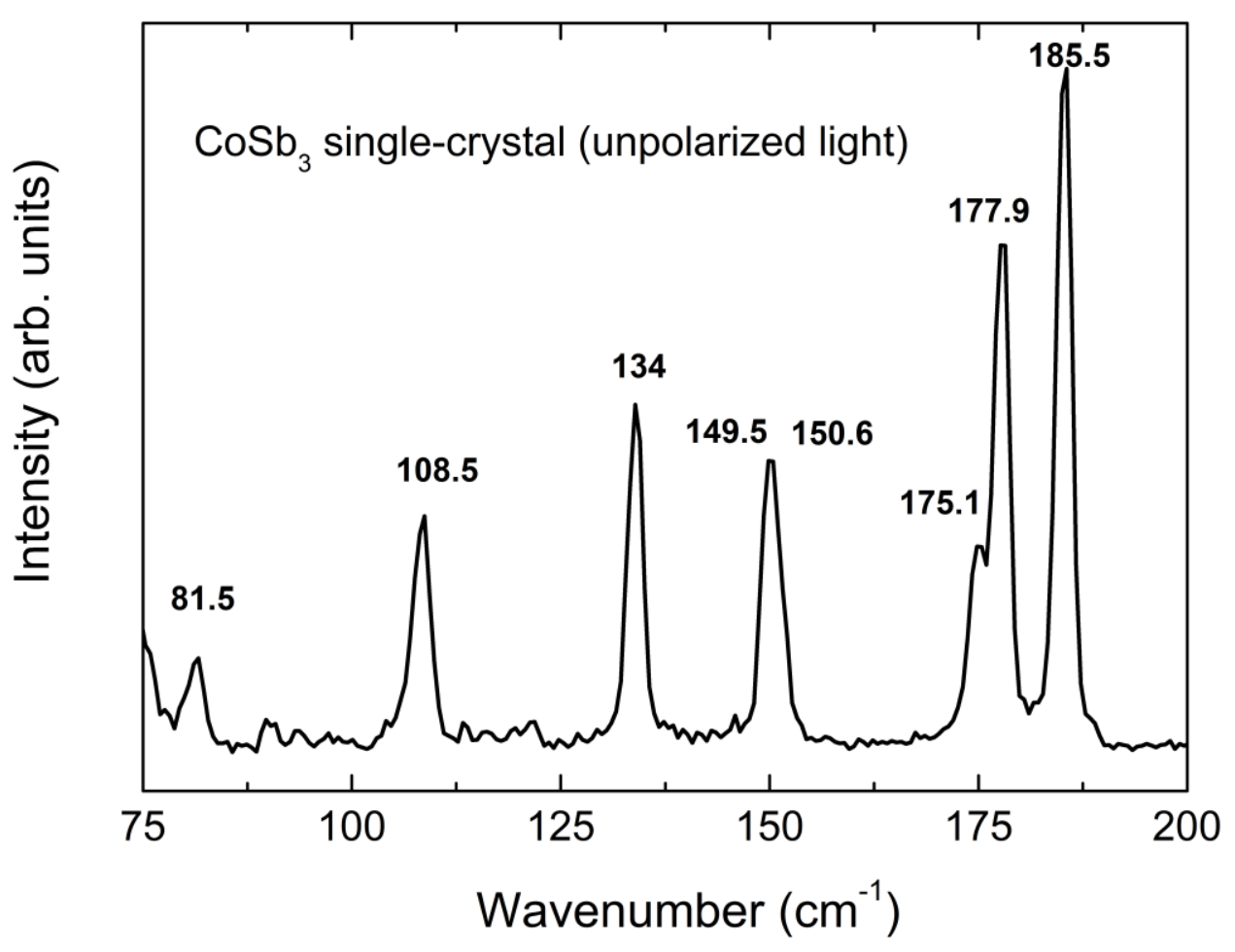

Figure 1 


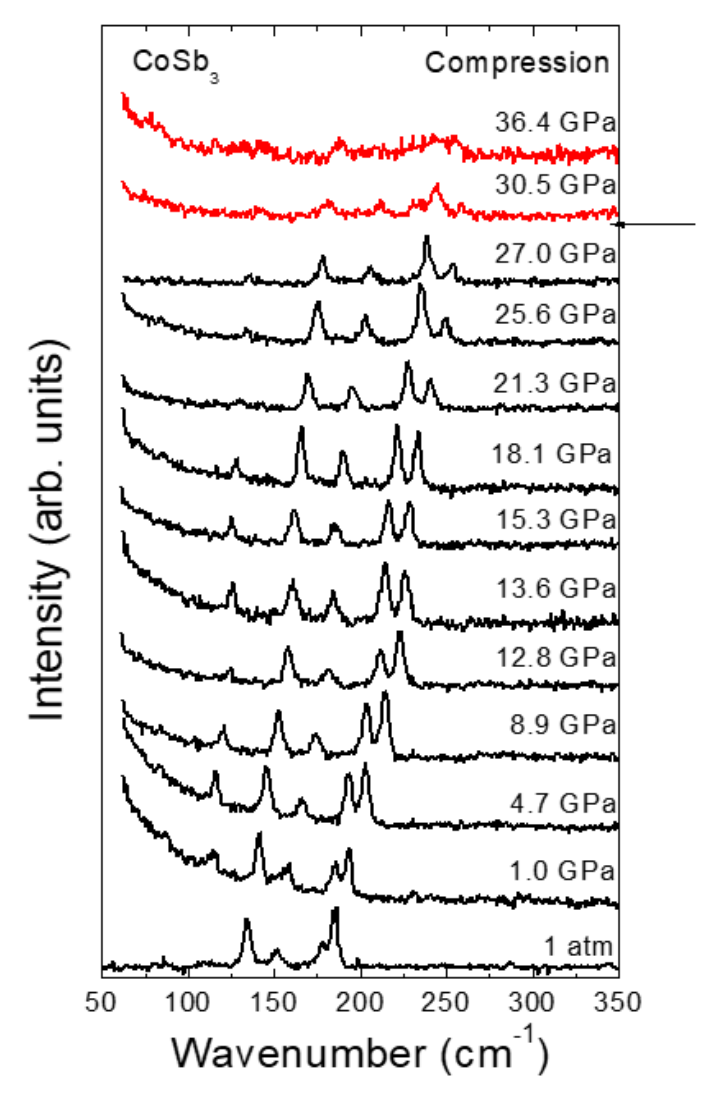

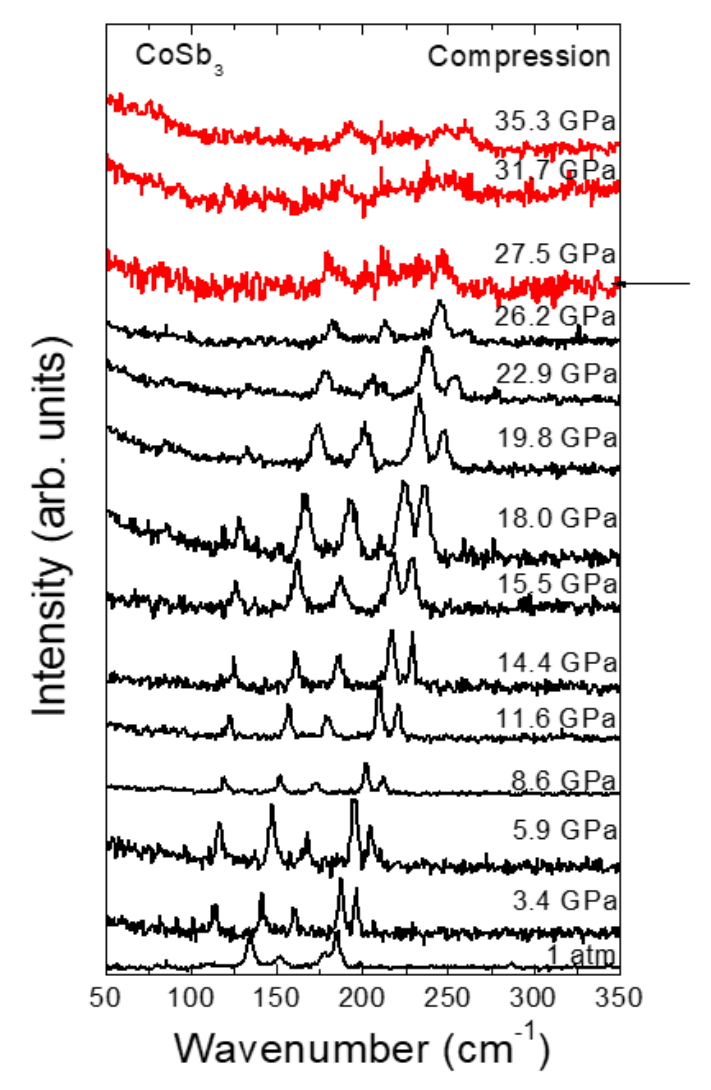

Figure 2 

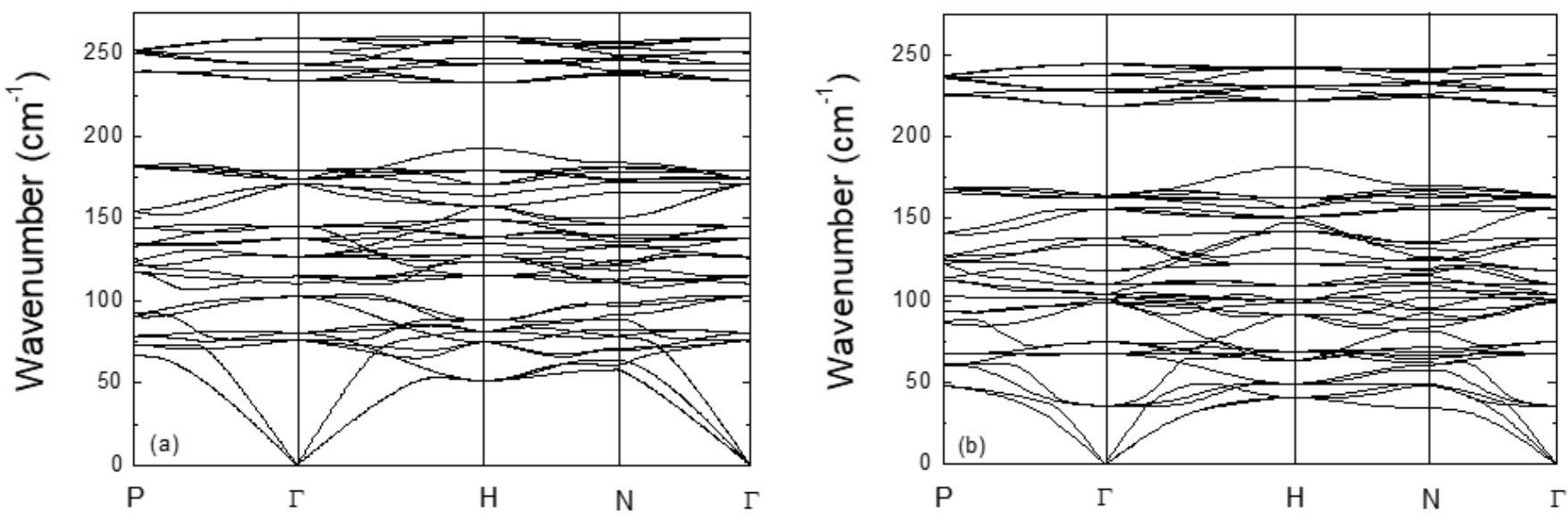

Figure 3 

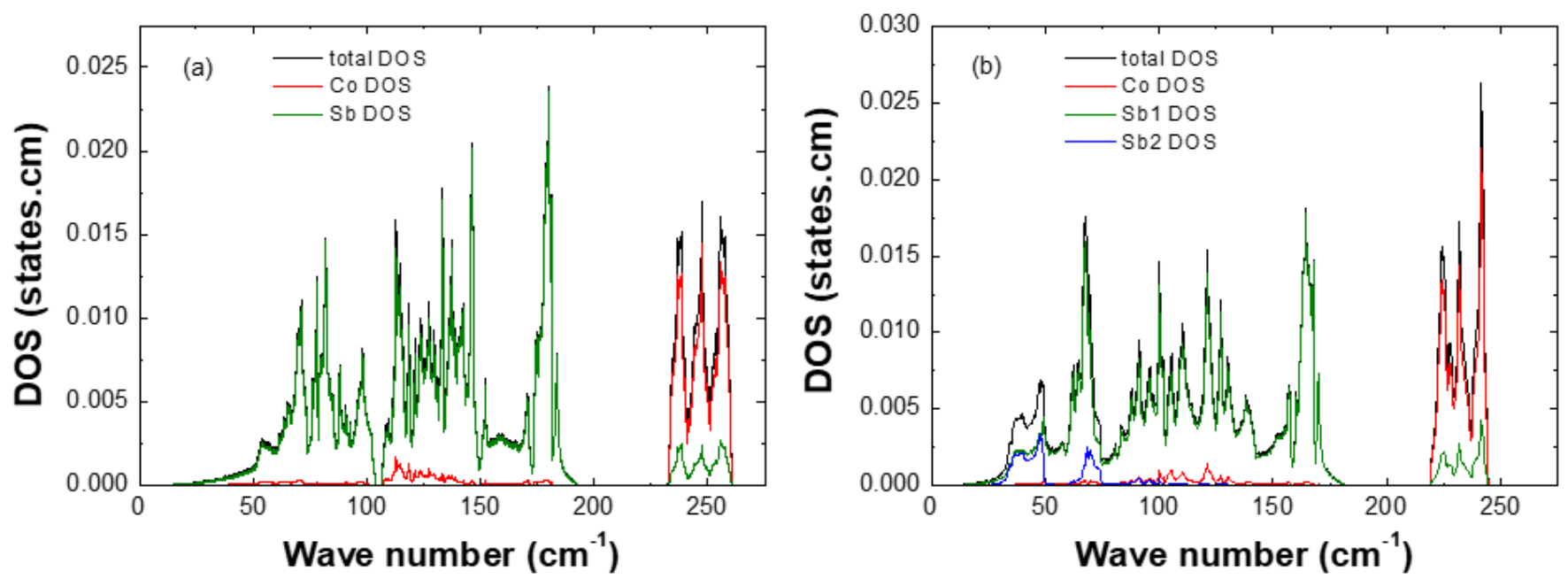

Figure 4 


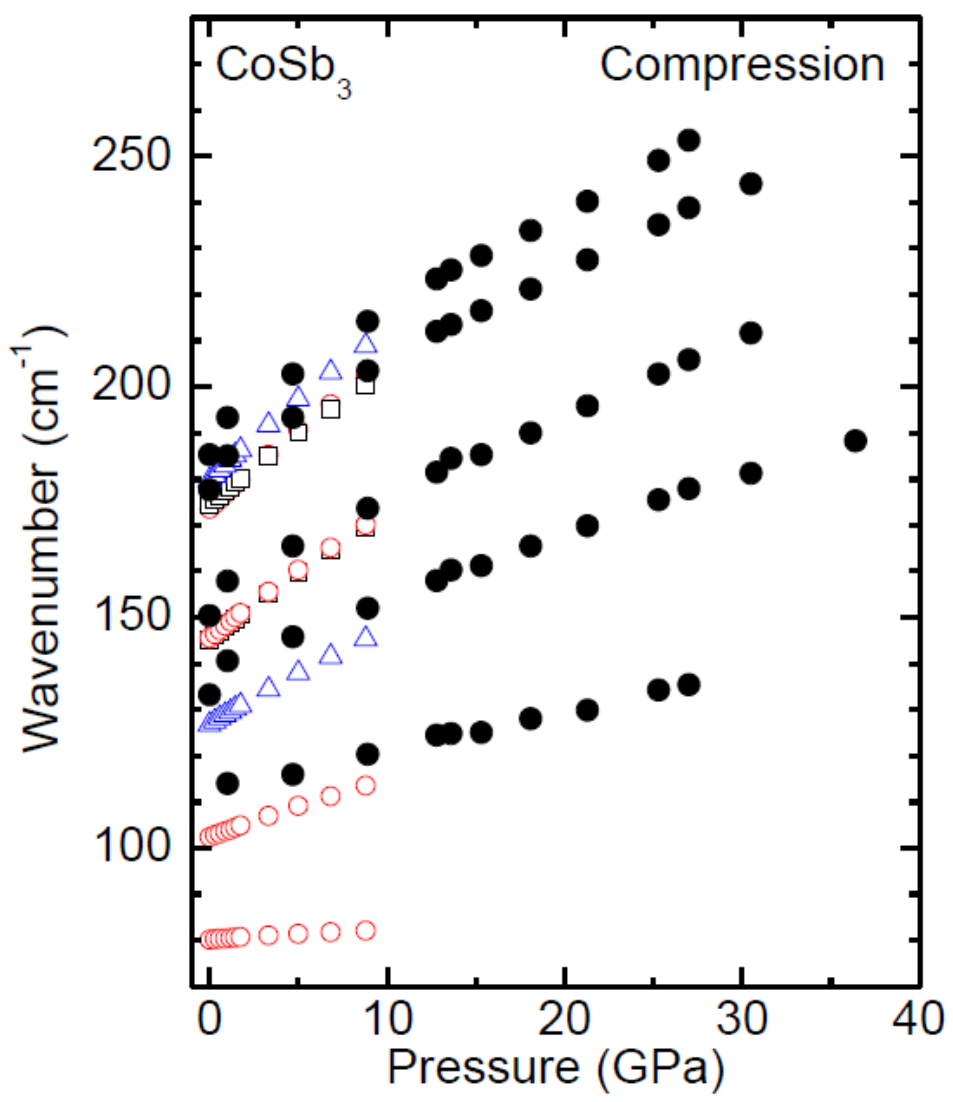

Figure 5 


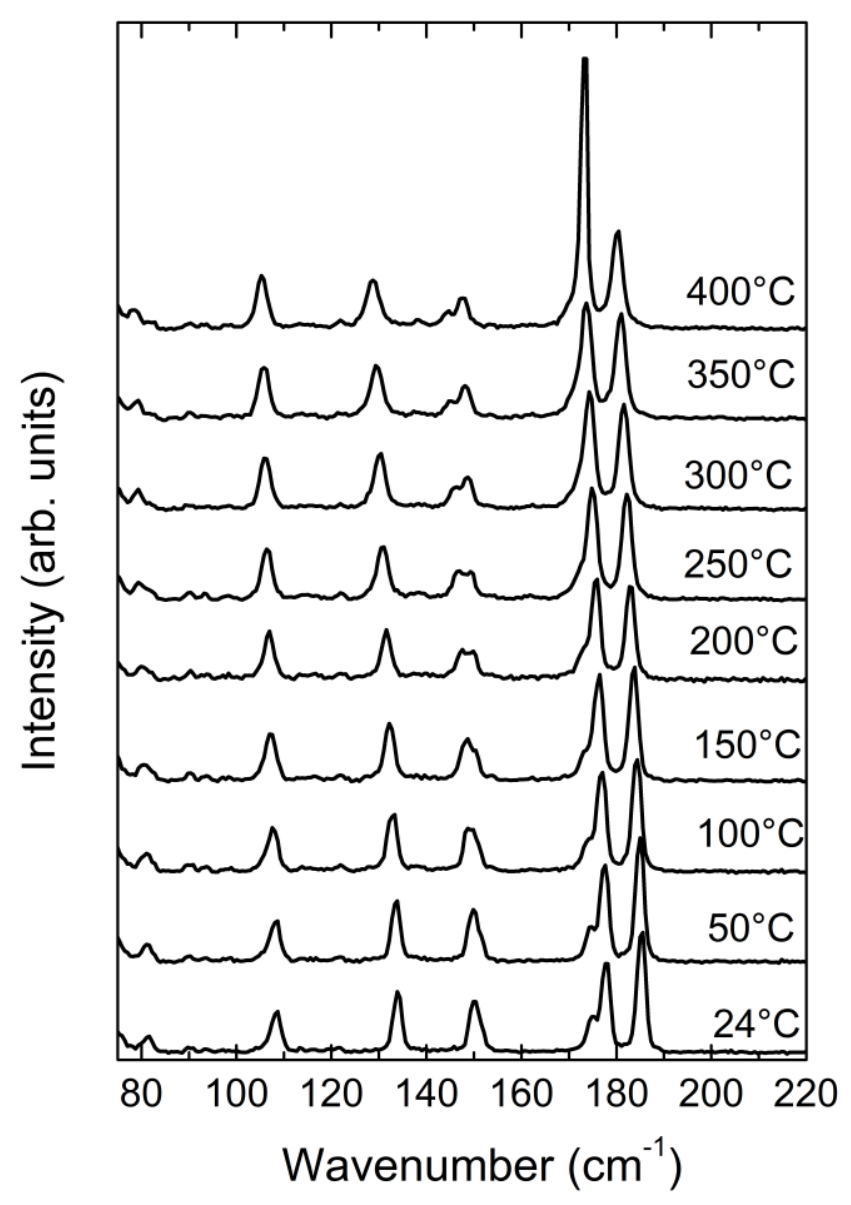

Figure 6 
(a)

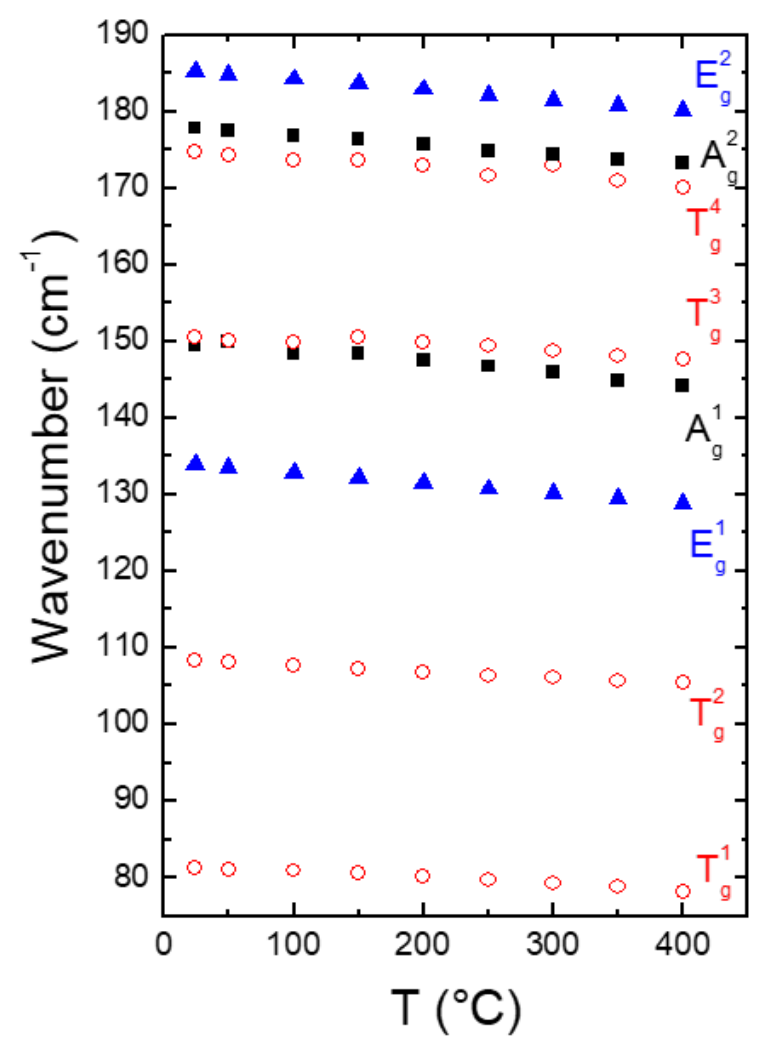

(b)

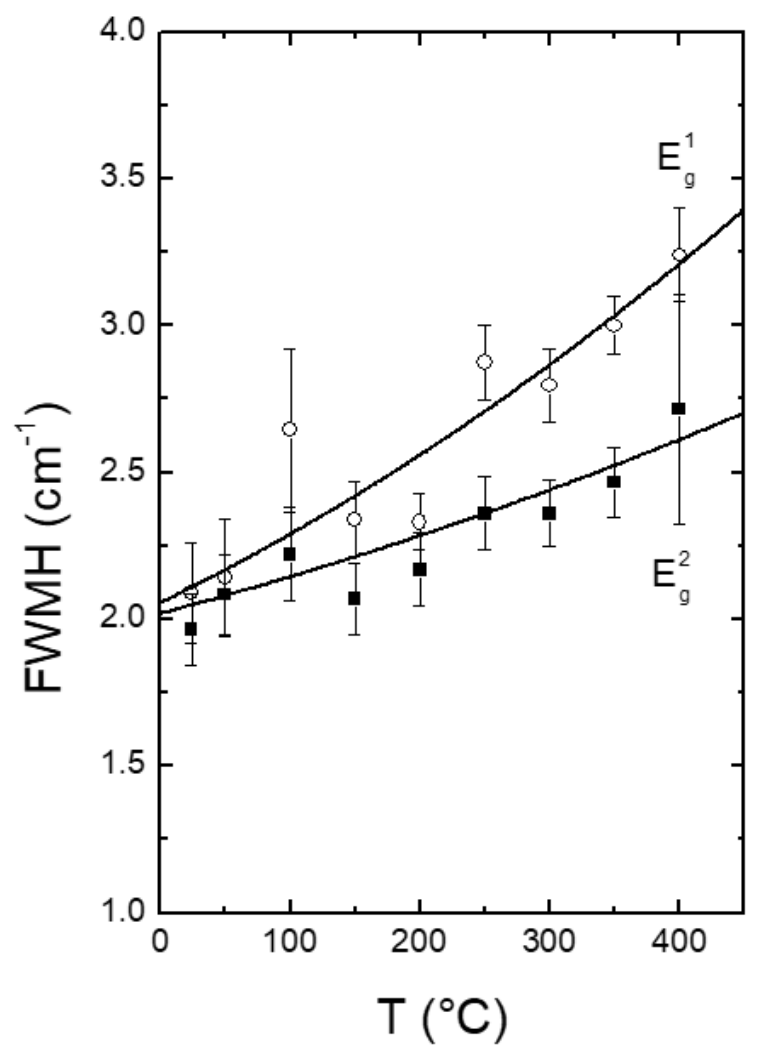

Figure 7 


\section{TOC graphic}
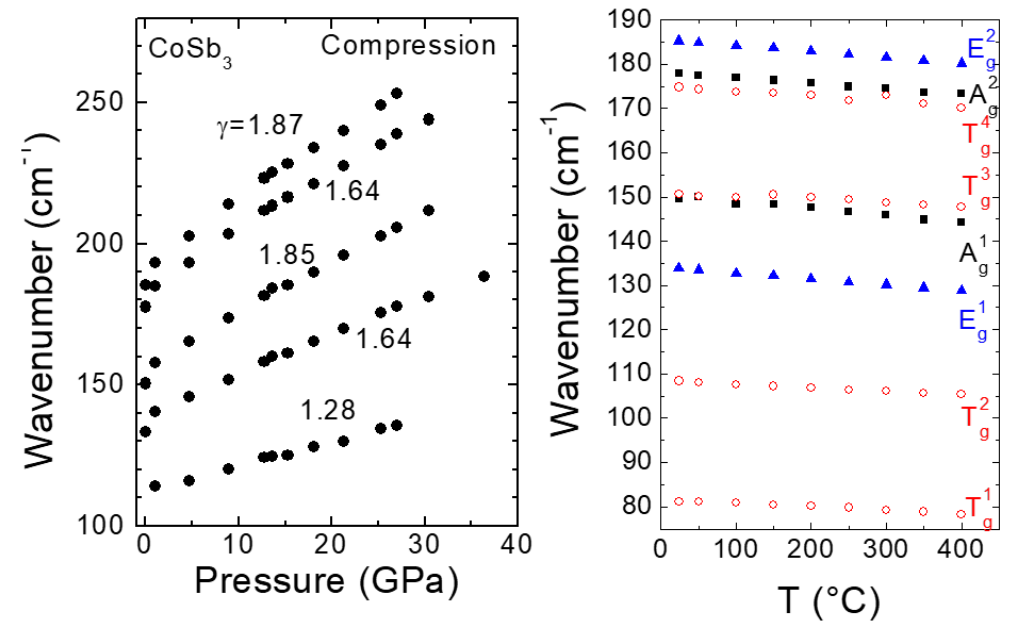